\title{
RENDIMENTO E CRESCIMENTO DA BETERRABA EM FUNÇÃO DA ADUBAÇÃO COM FÓSFORO'
}

\section{YIELD AND GROWTH OF THE BEET IN FUNCTION OF THE FERTILIZATION WITH PHOSPHORUS}

\author{
Cíntia Carla AVALHAES ${ }^{1}$ \\ Renato de Mello PRADO² \\ Ancélio Ricardo de Oliveira GONDIM ${ }^{3}$ \\ Adriana Ursulino ALVES ${ }^{3}$ \\ Marcus André Ribeiro CORREIA ${ }^{3}$
}

\begin{abstract}
RESUMO
Com objetivo de avaliar o rendimento e o crescimento das plantas de beterraba, cultivar Early Wonder, em função de doses de fósforo, um experimento foi conduzido em casa de vegetação no campus da FCAV-UNESP, Jaboticabal-SP. O delineamento experimental utilizado foi inteiramente casualizado, com quatro repetições e seis tratamentos, sendo estes compostos pelas seguintes doses de fósforo: 0; 50; 100; 150; 200 e $400 \mathrm{mg} \mathrm{dm}^{-3}$. Durante a condução do experimento, avaliou-se a altura e o número de folhas, a cada dez dias após o transplantio e ao final do ciclo (60 dias após o transplantio) foram avaliados a área foliar, o diâmetro da raiz tuberosa, a massa seca, o teor e o acúmulo de fósforo na planta e o teor de $\mathrm{P}$ no solo. A aplicação de fósforo promoveu incremento no crescimento, no teor foliar de $\mathrm{P}$ e na produção da beterraba. A regressão indicou que a dose de $340 \mathrm{mg} \mathrm{dm}^{-3}$ de $\mathrm{P}$ proporcionou maior massa de raiz tuberosa, esteve associado com a concentração de $\mathrm{P}$ no solo, de $54,3 \mathrm{mg} \mathrm{dm}^{-3}$; e com o teor de $\mathrm{P}$ na parte aérea e raiz tuberosa de 4,7 e 2,2 $\mathrm{g} \mathrm{kg}^{-1}$, respectivamente.

Palavras-chave: Beta vulgaris; diagnose foliar; adubação fosfatada.
\end{abstract}

\begin{abstract}
To evaluate the performance and growth of beet sugar plants, grow Early Wonder, depending on phosphorus levels. The experiment was conducted in a greenhouse on the campus of FCAV-UNESP, Jaboticabal-SP. The experimental design was completely randomized, with four replicates and six treatments, and these comprise the following phosphorus levels: 0 , $50,100,150,200$ and $400 \mathrm{mg} \mathrm{dm}^{-3}$. During the conduct of the trial was to assess the height and number of leaves, the ten days after transplanting and the end of the cycle (60 days after transplanting) were measured leaf area, the diameter of the tuberous root, the dry mass, the content and accumulation of phosphorus in the plant and content of phosphorus in the soil. The application of phosphorus increased in growth, leaf content of $\mathrm{P}$ and the beet. The decline indicated that the dose of 340 $\mathrm{mg} \mathrm{dm}^{-3}, \mathrm{P}$ provided the greatest mass tuberous root, was associated with the concentration of $\mathrm{P}$ in the soil, from $54,3 \mathrm{mg}$ $\mathrm{dm}^{-3}$, and with the content of $P$ in the shoots and tuberous root of 4.7 and $2.2 \mathrm{~g} \mathrm{~kg}^{-1}$, respectively.
\end{abstract}

Key-words: Beta vulgaris; diagnose leaf; phosphate fertilization.

1 Pós-graduanda em Agronomia (Ciência do Solo), Departamento de Solos e Adubos, Faculdade de Ciências Agrárias e Veterinárias (FCAV), UniversidadeEstadual Paulista Júlio de Mesquita Filho (UNESP). Via de acesso Prof. Paulo Donato Castellane, s/n. CEP: 14884-900, Jaboticabal - SP, Brasil. E-mail: cintiavalhaes@hotmail.com. Autora para correspondência.

2 Prof. Dr., Departamento de Solos e Adubos, Faculdade de Ciências Agrárias e Veterinárias, UniversidadeEstadual Paulista Júlio de Mesquita Filho. Jaboticabal - SP, Brasil. E-mail: rmprado@fcav.unesp.br.

3 Pós-graduando(a) em Agronomia (Produção Vegetal), Departamento de Solos e Adubos, Faculdade de Ciências Agrárias e Veterinárias, UniversidadeEstadual Paulista Júlio de Mesquita Filho. Jaboticabal - SP, Brasil. E-mail: anceliogondim@hotmail.com; adrianaursulino@hotmail.com; marcus.agro@hotmail.com 


\section{INTRODUÇÃO}

A produção de beterraba é uma das mais significativas do mercado nacional de hortaliças, existindo hoje no Brasil cerca de $10 \mathrm{mil}$ ha desta hortaliça, produzidos em mais de $100 \mathrm{mil}$ propriedades. No ano de 2006, o volume comercializado foi superior a 18 mil t (AGRIANUAL, 2007).

A grande maioria dos solos brasileiros é de reação ácida e de baixa fertilidade e elevada capacidade de retenção de fósforo o que leva à necessidade de aplicação de elevadas doses deste nutriente, contribuindo para o aumento nos custos de produção, e redução nos recursos naturais não renováveis que originam esses insumos (Moura et al., 2001).

A importância do fósforo para o crescimento das plantas está relacionada ao papel na síntese de proteínas, por constituir nucleoproteínas necessárias à divisão celular, atuar no processo de absorção iônica (Malavolta, 2006). Assim, o fósforo favorece o desenvolvimento do sistema radicular de hortaliças aumentando a absorção de água e de nutrientes; aumenta a qualidade e o rendimento dos produtos colhidos.

Scaife \& Turner (1983) classificaram a beterraba como hortaliça com baixa resposta à aplicação de fósforo. De forma geral, nota-se contradição na literatura, onde há relatos de que as hortaliças apresentam alta resposta à adubação fosfatada (Fontes et al., 1997; Vieira et al., 1998; Silva et al., 2001; Lana et al., 2004). Contudo, pesquisas sobre os efeitos do fósforo na nutrição e produção da beterraba são escassas, o que é motivo de preocupação para o manejo adequado da adubação dessa cultura.

Diante disso, este trabalho teve como objetivo avaliar os efeitos da aplicação de fósforo no rendimento e crescimento da beterraba.

\section{MATERIAL E MÉTODOS}

$O$ experimento foi implantado em casa de vegetação na FCAV/Unesp Campus Jaboticabal-SP, com coordenadas geográficas $21^{\circ} 15^{\prime} 22^{\prime \prime}$ Sul, 48 $18^{\prime} 58^{\prime \prime}$ Oeste e altitude de $575 \mathrm{~m}$, com a cultura da beterraba, cultivar Early Wonder, no período de agosto a setembro de 2007.

O delineamento experimental utilizado foi inteiramente casualizado com seis tratamentos e quatro repetições. Os tratamentos foram compostos pelas doses de fósforo: 0 (testemunha); 50; 100; 150; 200 e $400 \mathrm{mg} \mathrm{dm}^{-3}$, fornecidas na forma de superfosfato triplo.

Cada vaso com capacidade de $4 \mathrm{dm}^{3}$ foi preenchido com $3 \mathrm{dm}^{3}$ de um Latossolo Vermelho Distrófico peneirado com peneira de malha de $5 \mathrm{~mm}$, textura média (EMBRAPA, 1999). A análise química inicial do solo foi realizada segundo Raij et al. (2001), apresentando os seguintes resultados: $\mathrm{pH}=4,2 ; \mathrm{MO}$ $=17 \mathrm{~g} \mathrm{dm}^{-3} ; \mathrm{P}=5 \mathrm{mg} \mathrm{dm}^{-3} ; \mathrm{K}=0,5 \mathrm{mmol}_{\mathrm{c}} \mathrm{dm}^{-3} ; \mathrm{Ca}=4$ $\mathrm{mmol}_{\mathrm{c}} \mathrm{dm}^{-3} ; \mathrm{Mg}=2 \mathrm{mmol}_{\mathrm{c}} \mathrm{dm}^{-3} ;(\mathrm{H}+\mathrm{Al})^{\mathrm{C}}=58 \mathrm{mmol}_{c}$ $\mathrm{dm}^{-3} ; \mathrm{SB}=6,5 ; \mathrm{CTC}=64,5 \mathrm{mmol}^{\mathrm{C}} \mathrm{dm}^{-3} ; \mathrm{V}=10 \%$. Periodicamente foi realizado o rodízio dos vasos.
A partir dos dados obtidos através da análise de solo seguiu-se a correção da acidez, com objetivo de elevar o pH conforme Raij et al. (1997), utilizando um material corretivo com as seguintes características: $\mathrm{PRNT}=125 \%, 580 \mathrm{~g} \mathrm{~kg}^{-1}$ de $\mathrm{CaO}, 90$ $\mathrm{g} \mathrm{kg}^{-1}$ de $\mathrm{MgO}$. Incubou-se o solo por 30 dias, em sacos plásticos, abertos com umidade próxima a $60 \%$ da capacidade máxima de retenção de água, sendo revolvidos constantemente.

A adubação básica, incorporada ao volume de solo, ainda na ocasião do plantio, recebeu as doses de nivelamento para $\mathrm{N}\left(300 \mathrm{mg} \mathrm{dm}^{-3}\right), \mathrm{K}(150$ $\left.\mathrm{mg} \mathrm{dm}^{-3}\right), \mathrm{Zn}\left(2 \mathrm{mg} \mathrm{dm}^{-3}\right), \mathrm{B}\left(0,5 \mathrm{mg} \mathrm{dm}^{-3}\right)$, baseadas na recomendação de Malavolta (1981), tendo como fontes o sulfato de amônio, o cloreto de potássio, o sulfato de zinco e o ácido bórico $\left(170 \mathrm{~g} \mathrm{~kg}^{-1} \mathrm{de} \mathrm{B}\right)$, respectivamente.

A semeadura foi realizada em bandejas de 200 células em substrato comercial Bioplant ${ }^{\circledR}$ sem adubação. Após 30 dias da semeadura, as plantas foram transferidas para os vasos.

Inicialmente foram transplantadas duas mudas e após dez dias do transplantio, foi realizado o desbaste visando conduzir apenas uma planta por vaso. A irrigação diária foi realizada, visando manter a umidade correspondente a $60 \%$ da capacidade de retenção, utilizando água desionizada.

As avaliações durante a condução do experimento foram realizadas através de medições da altura da planta, número de folhas (a cada dez dias após o transplantio), área foliar e diâmetro da raiz tuberosa (no final do ciclo, aos 60 dias após o transplantio), massas seca e fresca da parte aérea e raiz. A parte aérea e as raízes tuberosas foram lavadas em água destilada para remover o substrato e, posteriormente seca em estufa de circulação forçada de ar à temperatura de $65^{\circ} \mathrm{C}$. Quantificouse a massa seca tanto da parte aérea como das raízes tuberosas. Em seguida, o material foi moído e realizada a análise química para determinação dos teores de $\mathrm{P}$, conforme método descrito por Bataglia et al. (1983), e calculou-se o acúmulo de P nesses órgãos. Realizou-se também a análise química do solo, determinando-se a concentração de P, conforme método descrito por Raij et al. (2001).

Por fim, realizou-se a análise de variância para as variáveis estudadas, bem como estudos de regressão polinomial, com auxílio do software SAS INSTITUTE (1996), e as figuras com as equações realizadas por meio do Microsoft Excel, a partir das quais se pode calcular o ponto de Máxima Eficiência Técnica $\left(M E T=-b /\left(2^{*} a\right)\right)$.

\section{RESULTADOS E DISCUSSÃO}

Observou-se diferença significativa para as variáveis analisadas, em função das doses de fósforo aplicadas. Com o aumento das doses de fertilizante fosfatado houve incremento linear de fósforo no solo (Figura 1). O incremento linear da concentração de $\mathrm{P}$ com a aplicação do fertilizante fosfatado já tem sido relatado na literatura, seja em um Latossolo Vermelho Distrófico (Prado et al., 2005) ou Latossolo Vermelho-Amarelo Álico (Nakayama et al., 1998). 
AVALHAES, C.C. et al. Rendimento e crescimento da beterraba...

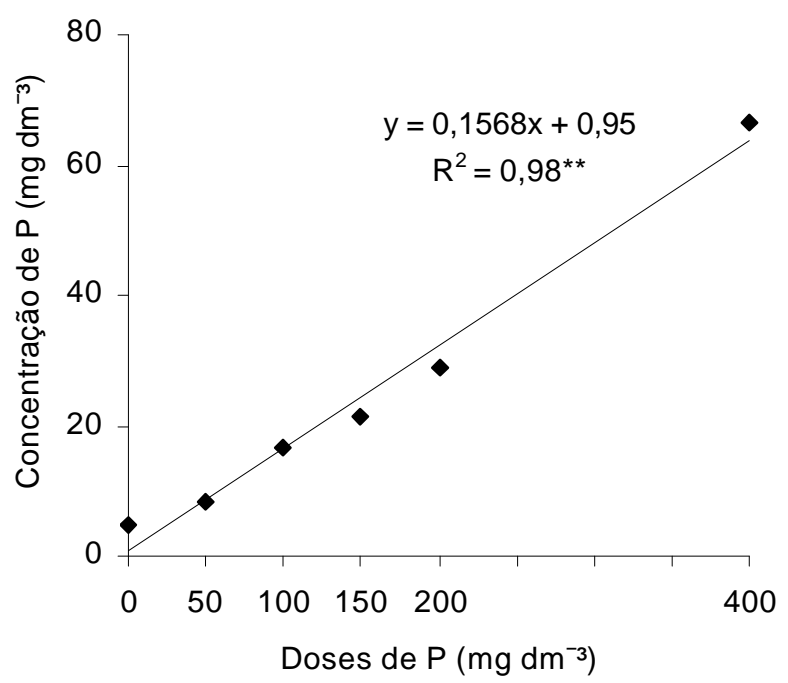

FIGURA 1 - Efeito da aplicação de doses de fósforo na concentração de P num Latossolo Vermelho Distrófico, cultivado com plantas de beterraba, em casa de vegetação.

Em relação ao desenvolvimento da cultura, observou-se um aumento quadrático na altura das plantas conforme o aumento das doses de fósforo aplicadas (Figura 2a), até a dose de $320 \mathrm{mg} \mathrm{dm}^{-3}$ (Máxima eficiência técnica - MET), conforme indicou

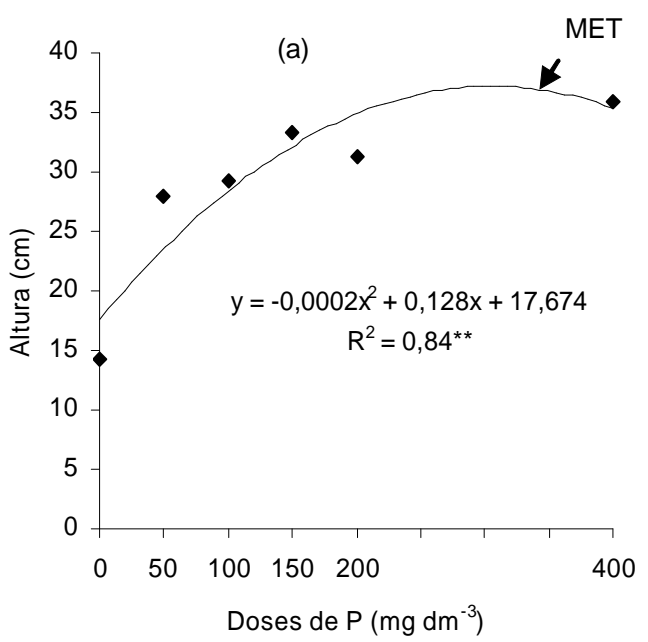

a regressão. Analisando os dados de área foliar, observa-se diferença significativa entre os tratamentos, sendo que as plantas que receberam a aplicação de $350 \mathrm{mg} \mathrm{dm}^{-3}$ apresentaram o maior valor (Figura $2 b$ ), conforme indicado pela regressão.

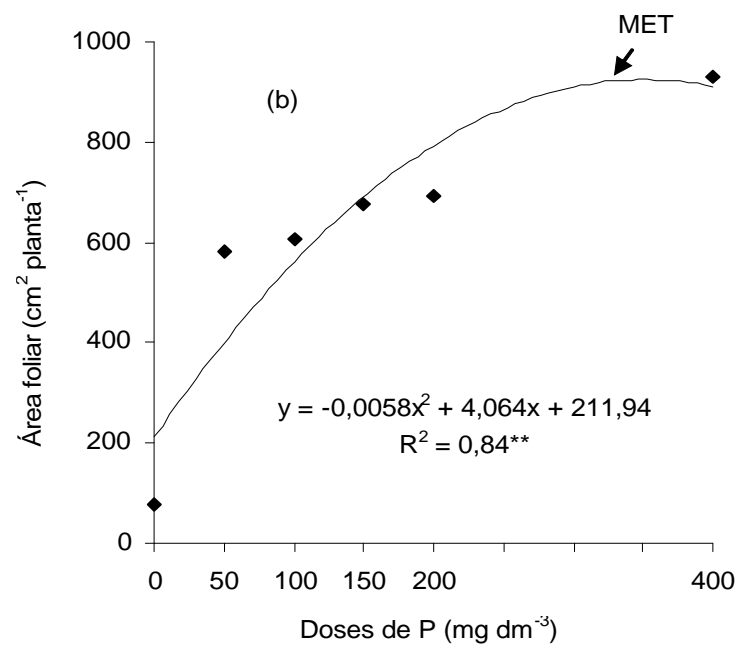

FIGURA 2 - Altura (a) e a área foliar (b) das plantas de beterraba na época da colheita, em função das doses de fósforo, cultivadas num Latossolo Vermelho Distrófico, em casa de vegetação. (MET - Ponto de máxima eficiência técnica).

A adubação fosfatada promoveu diferenças significativas nos teores de $\mathrm{P}$ na parte aérea e nas raízes das plantas de beterraba (Figura 3a), resultados semelhantes aos encontrados por Prado et al. (2005) em mudas de maracujá. Observou-se que a adubação fosfatada promoveu aumento de até 8,5 vezes, nos teores de $P$ na parte aérea; e de 1,5 vez em relação ao teor nas raízes, quando comparados aos teores na testemunha, em função do aumento do nutriente no solo (Figura 1).

Os teores de $P$ na parte aérea, conforme as doses de $\mathrm{P}$ foram: 0,$6 ; 1,4 ; 2,5 ; 2,6 ; 3,1$ e $5,2 \mathrm{~g}$ $\mathrm{kg}^{-1}$ de $\mathrm{P}$ e, na raiz tuberosa foram: 1,$6 ; 1,1 ; 1,4 ; 1,7$; 1,4 e $2,6 \mathrm{~g} \mathrm{~kg}^{-1}$ de $\mathrm{P}$ (Figura 3a). Esses valores quando comparados ao teor foliar de $\mathrm{P}$ considerado adequada por Trani \& Raij (1997) (2 a $4 \mathrm{~g} \mathrm{~kg}^{-1}$ ), indica que apenas as doses de 50 e $400 \mathrm{mg} \mathrm{dm}^{-3}$, estavam respectivamente abaixo e acima da faixa adequada segundo os referidos autores. Porém, Furlani et al. (1978) relataram teor de $P$ na parte aérea $\left(6,9 \mathrm{~g} \mathrm{~kg}^{-1}\right)$ e na raiz $\left(8,7 \mathrm{~g} \mathrm{~kg}^{-1}\right)$ da beterraba, maior que o obtido nesse trabalho. As diferenças nos teores de $P$ na planta dos autores possivelmente devem-se ao sistema de cultivo distinto, em solo relatado por Trani 
(a)

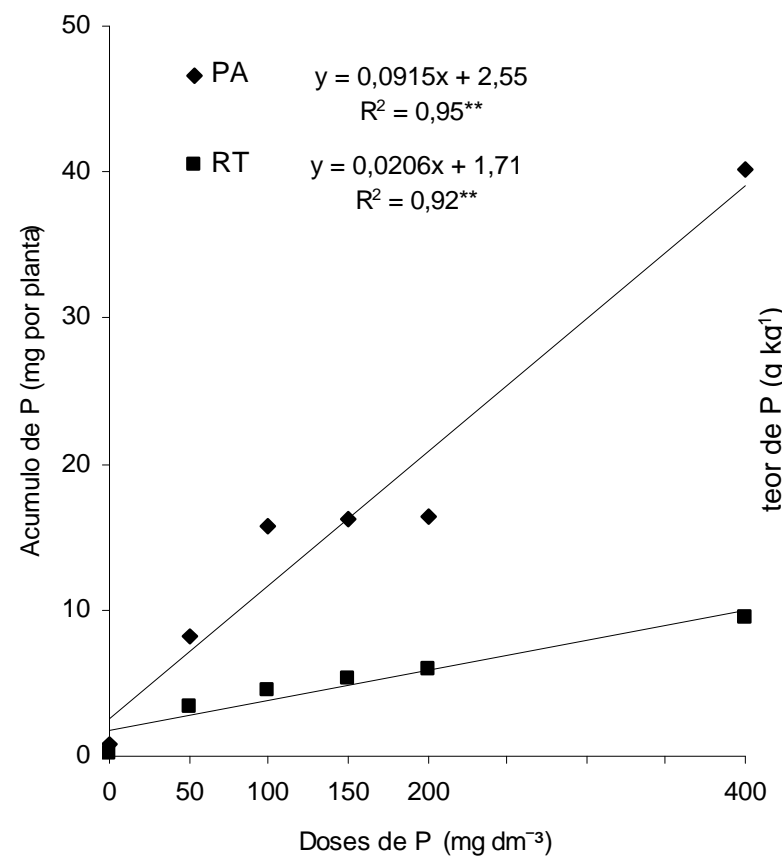

(b)

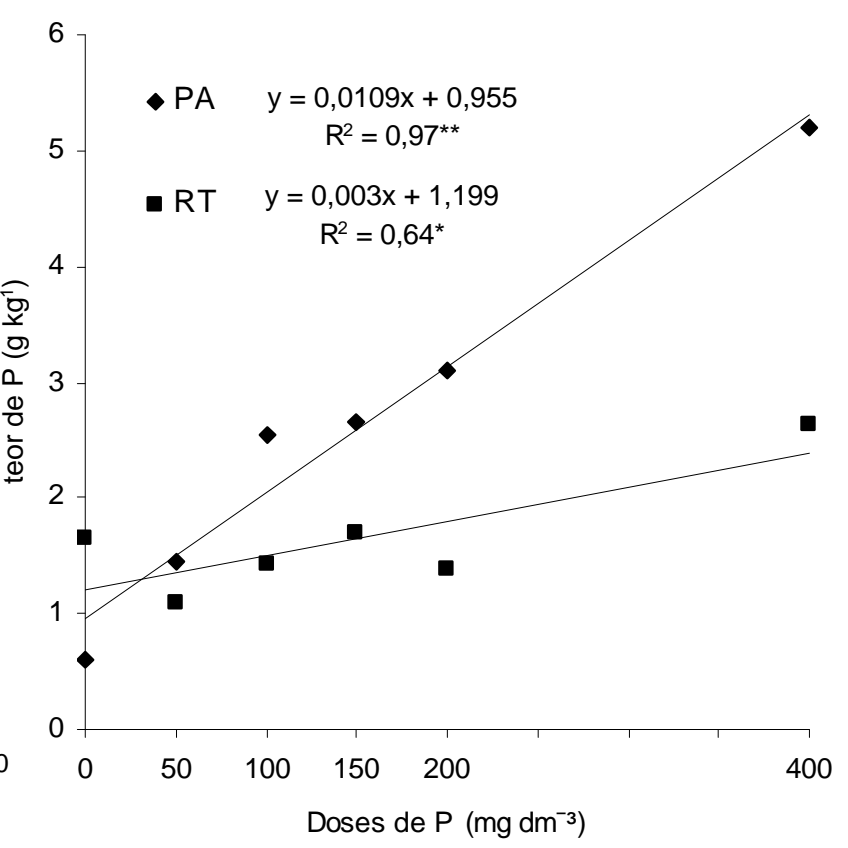

FIGURA 3 - Teor (a) e acúmulo (b) de fósforo na parte aérea (PA) e na raiz tuberosa (RT) de plantas de beterraba, em função de doses de fósforo, cultivadas num Latossolo Vermelho Distrófico, em casa de vegetação.

\& Raij (1997), e em solução nutritiva indicado por Furlani et al. (1978), sendo que esse último sistema por conter maior teor de $\mathrm{P}$ no meio de cultivo refletiria na planta. Alves et al. (2008) constataram em plantas de beterraba cultivada em solução nutritiva, um alto teor de $P$ na solução com presença do nutriente $(9,0$ e $7,0 \mathrm{~g} \mathrm{~kg}^{-1}$ de $P$ na parte aérea e na raiz, respectivamente), comparado à solução com a ausência do nutriente $\left(0,8\right.$ e $1,8 \mathrm{~g} \mathrm{~kg}^{-1}$ de $P$, na parte aérea e na raiz).

Observa-se que a aplicação de $P$, além de aumentar o teor de $P$ (Figuras $3 a)$, refletiu no incremento do acúmulo do nutriente, com ajuste linear, tanto na parte aérea $(0,8$ até $40,2 \mathrm{mg}$ por planta), como na raiz tuberosa $(0,2$ até $9,4 \mathrm{mg}$ por planta) (Figura $3 b$ ), sendo que no ponto de Máxima Eficiência Técnica, o acúmulo foi de 33,66 e 8,71 mg por planta, na parte aérea e nas raízes, respectivamente. Nota-se que a parte aérea acumulou maior quantidade de $P$ em relação às raízes. O P acumulado na planta da beterraba foi próximo aos encontrados por Haag \& Minami (1987). Entretanto, Grangeiro et al. (2007) observaram que o fósforo acumulou-se preferencialmente nas raízes da beterraba.

Da mesma forma que ocorreu com as variáveis de crescimento, como altura (Figura 2a), área foliar (Figura 2b), diâmetro da raiz tuberosa (Figura 4a) e massa fresca da raiz tuberosa (Figura $4 b)$, houve reflexos, também, na massa seca da planta (Figura 5). Esse resultado discorda de Scaife \& Turner (1983), que classificaram a beterraba como uma hortaliça com resposta relativamente baixa ao fósforo. O efeito positivo do $P$ na produção de massa seca das plantas é amplamente relatado na literatura em diversas culturas (Prado et al., 2005; Lana et al., 2004; Oliveira et al., 2004; Moura et al., 2001). E salienta-se que as plantas da testemunha (dose 0 de $P$ ), além de não apresentarem desenvolvimento da raiz tuberosa e parte aérea reduzida, apresentaram sintomas de deficiência, como avermelhamento das folhas. Alves et al. (2008), trabalhando com omissão de fósforo em solução nutritiva, verificaram arroxeamento intenso das folhas e raízes, e paralisação do crescimento da raiz tuberosa. Este fato ocorre devido ao nutriente afetar vários processos do metabolismo da planta, como a síntese protéica e de ácidos nucléicos (Mengel \& Kirkby,1987).

Nota-se que, pela regressão, a dose de 340 $\mathrm{mg} \mathrm{dm}^{-3}$ de $\mathrm{P}$ que proporcionou a maior massa fresca da raiz tuberosa (Figura 4b), indicada pela regressão, estando associada com teor foliar de $\mathrm{P}$, de $4,7 \mathrm{~g} \mathrm{~kg}^{-1}$, e, portanto, pouco acima da faixa adequado indicada por Trani \& Raij (1997) (2 a $4 \mathrm{~g} \mathrm{~kg}^{-1}$ ). Isso se deveu ao fato deste experimento ter sido conduzido em vaso, já o dos autores citados acima referem-se a teores de nutrientes de plantas cultivadas a campo.

\section{CONCLUSÕES}

A aplicação de fósforo promoveu incremento no crescimento, no teor foliar de P e na massa fresca da raiz tuberosa da beterraba. A regressão indicou que a dose de $340 \mathrm{mg} \mathrm{dm}^{-3}$ de $\mathrm{P}$ que proporcionou maior massa fresca da raiz tuberosa, e esteve associada com a concentração de $\mathrm{P}$ no solo, de $54,3 \mathrm{mg} \mathrm{dm}^{-3}$; e com o teor de $\mathrm{P}$ na parte aérea e raiz tuberosa de 4,7 e $2,2 \mathrm{~g} \mathrm{~kg}^{-1}$, respectivamente. 
(a)

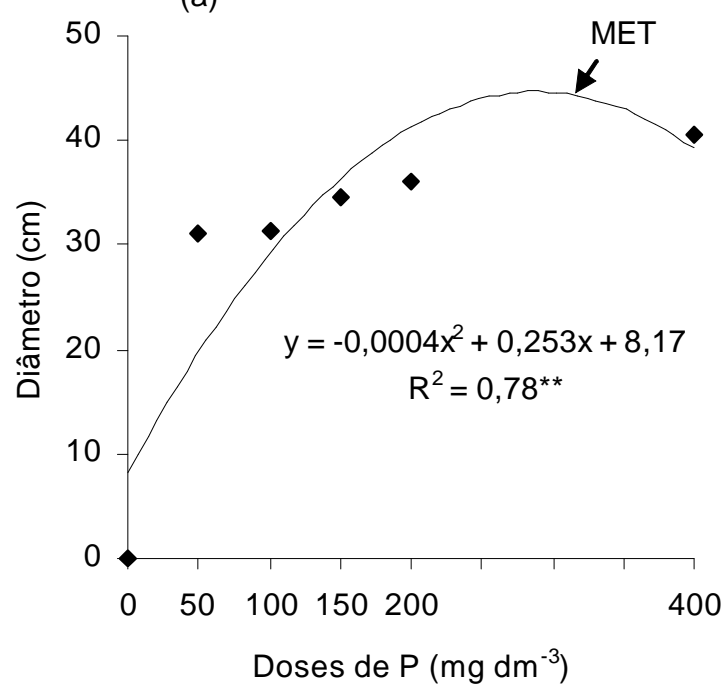

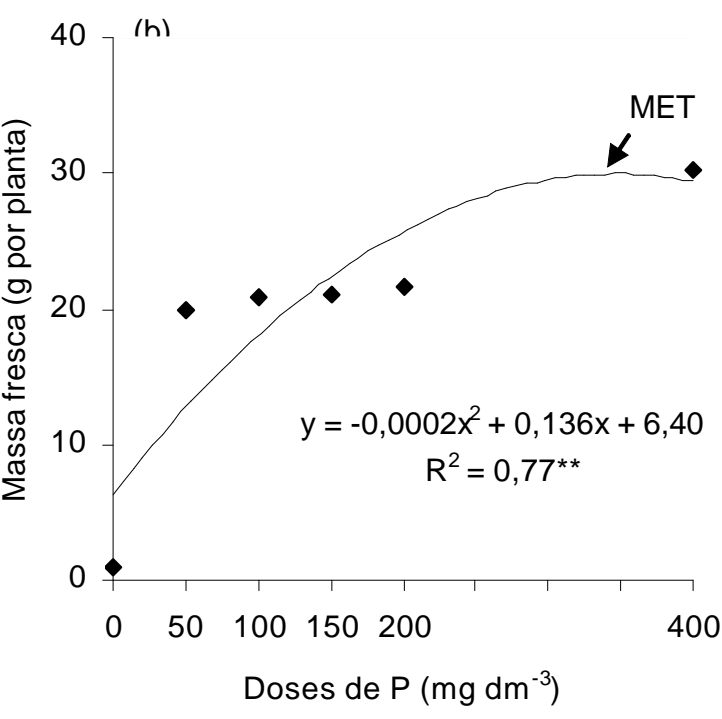

FIGURA 4 - Diâmetro (a) e massa fresca da raiz tuberosa (b) das plantas de beterraba, em função das doses de fósforo, cultivadas num Latossolo Vermelho Distrófico, em casa de vegetação.

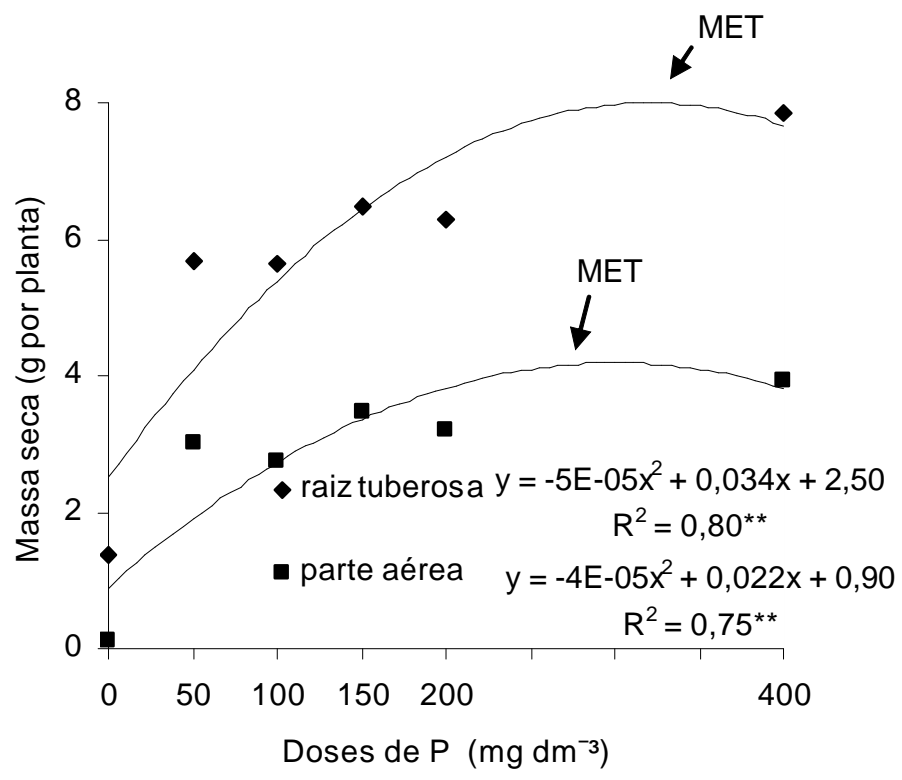

FIGURA 5 - Massa seca da parte aérea e da raiz tuberosa de plantas de beterraba, em função das doses de fósforo, cultivadas num Latossolo Vermelho Distrófico, em casa de vegetação.

\section{REFERÊNCIAS}

1. ALVES, A. U. et al. Desenvolvimento e estado nutricional da beterraba em função da omissão de nutrientes. Horticultura Brasileira, v. 26, n. 2, p. 292-295, 2008.

2. ANUÁRIO DA AGRICULTURA BRASILEIRA (AGRIANUAL). Agrianual, 2007. São Paulo: Instituto FNP, 2007. 516 p.

3. BATAGLIA, O. C. et al. Métodos de análise química de plantas. Campinas: IAC, 1983. 48 p.

4. EMPRESA BRASILEIRA DE PESQUISA AGROPECUÁRIA (EMBRAPA). Centro Nacional de Pesquisa de Solo. Sistema Brasileiro de Classificação de Solos. Brasília: Embrapa Produção de Informações, 1999. 412 p.

5. FONTES, P. C. R.; ROCHA, F. A.T.; MARTINEZ, H. E. P. Produção de máxima eficiência econômica da batata em função da adubação fosfatada. Horticultura Brasileira, v. 15, n. 2, p. 104-107, 1997.

6. FURLANI, A. M. C. et al. Composição mineral de diversas hortaliças. Bragantia, v. 37, n. 5, p. 33-44, 1978.

7. GRANGEIRO, L. C. et al. Acúmulo e exportação de nutrientes em beterraba. Ciência e Agrotecnologia, v. 31, n. 2 , p. 267-273, 2007

8. HAAG, H. P.; MINAMI, K. Nutrição mineral de hortaliças: LXIII requerimento de nutrientes pela cultura da beterraba. Anais da Escola Superior de Agricultura "Luiz de Queiroz", v. 44, p. 401-407, 1987. 
AVALHAES, C.C. et al. Rendimento e crescimento da beterraba...

9. LANA, R. M. Q. et al. Produção de alface em função do uso de diferentes fontes de fósforo em solos de Cerrado. Horticultura Brasileira, v. 22, n. 3, p. 525-528, 2004.

10. MALAVOLTA, E. Manual de nutrição de plantas. São Paulo: Editora Agronômica Ceres, 2006. 638 p.

11. MALAVOLTA, E. Manual de química agrícola: adubos e adubações. 3. ed. São Paulo: Agronômica Ceres, 1981. 596

12. MENGEL, K; KIRKBY, E. A. Principles of plants nutrition. Bern: International Potash Institute, 1987. 687 p.

13. MOURA, W. M. et al. Eficiência nutricional para fósforo em linhagens de pimentão. Horticultura Brasileira, v. 19, n. 3, p. 306-312, 2001.

14. NAKAYAMA, L. H. I. et al. Eficiência relativa de fontes de fósforo de diferentes solubilidades na cultura do arroz. Scientia Agricola, v. 55, n. 2, p. 183-190, 1998.

15. OLIVEIRA, A.P. et al. Produção de feijão-fava em função do uso de doses de fósforo. Horticultura Brasileira, v. 22, n. 3, p. 543-546, 2004.

16. PRADO, R. M.; VALE, D. W.; ROMUALDO, L. M. Fósforo na nutrição de mudas de maracujazeiro. Acta Scientiarum Agronomy, v. 27, n. 3, p. 493-498, 2005.

17. RAlJ, B. van. et al. Recomendações de adubação e calagem para o estado de São Paulo. 2. ed. rev. atual. Campinas: Instituto Agronômico/Fundação IAC, 1997. 285 p. (Boletim técnico, 100).

18. RAIJ, B. van. et al. Análise química para avaliação da fertilidade de solos tropicais. Campinas: Instituto Agronômico, 2001. 285 p.

19. SAS INSTITUTE. The SAS-system for windows: release 6.11 (software). Cary: Statistical Analysis System Institute, 1996.

20. SCAIFE, A.; TURNER, M. Diagnosis of mineral disordens in plants. In: ROBISON, J. B. D. (Ed.). Vegetables. v. 2. London: University of Bristol, 1983. $95 \mathrm{p}$

21. SILVA, E. C.; MIRANDA, J. R. P.; ALVARENGA, M. A. R. Concentração de nutrientes e produção do tomateiro podado e adensado em função do uso de fósforo, de gesso e de fontes de nitrogênio. Horticultura Brasileira, v. 19, n. 1, p. 64-69, 2001.

22. TRANI, P. E.; RAIJ, B. van. Hortaliças. In: RAIJ B. van. et al. Recomendações de adubação e calagem para o estado de São Paulo. 2. ed. rev. atual. Campinas: Instituto Agronômico/ Fundação IAC, 1997. 285 p. (Boletim técnico, $100)$.

23. VIEIRA, M. C. et al. Crescimento e produção de mandioquinha-salsa em função da adubação fosfatada e da utilização de cama-de-aviário. Horticultura Brasileira, v. 16, n. 1, p. 68-73, 1998.

Recebido em 01/07/2008 Aceito em 31/10/2008 